\title{
Vivências de Mães e Bebês Prematuros durante a Internação Neonatal
}

\author{
Denice Bortolin Baseggio \\ Programa de Pós-Graduação em Psicologia Clínica da Universidade \\ do Vale do Rio dos Sinos, São Leopoldo, RS, Brasil \\ Escola de Psicologia da IMED, Passo Fundo, RS, Brasil \\ Marta Priscila Schneider Dias ${ }^{1}$ \\ Simone Rodigheri Brusque \\ Faculdade Meridional/IMED, Passo Fundo, RS, Brasil \\ Tagma Marina Schneider Donelli \\ Programa de Pós-Graduação em Psicologia Clínica da Universidade \\ do Vale do Rio dos Sinos, São Leopoldo, RS, Brasil \\ Patricia Mendes \\ Faculdade Meridional/IMED, Passo Fundo, RS, Brasil
}

\begin{abstract}
Resumo
O significativo aumento de nascimentos de bebês prematuros no Brasil, principal causa de morte até os 28 dias de vida do bebê, tem preocupado os diferentes profissionais da área de saúde. Diante desta realidade, investigou-se como as mães e bebês prematuros vivenciam o período de internação em uma Unidade de Tratamento Intensivo Neonatal, em um Hospital do Interior do Rio Grande do Sul. Trata-se de uma pesquisa qualitativa, com delineamento de estudos de casos múltiplos. Participaram três bebês prematuros que nasceram com menos de 37 semanas e com peso inferior a $2.500 \mathrm{Kg}$, de ambos os gêneros, que necessitaram permanecer em atendimento na Unidade de Tratamento Intensivo Neonatal (UTIN) entre o primeiro mês de vida, e suas respectivas mães. Os instrumentos foram: entrevista semiestruturada; prontuário médico dos bebês e sessões de observação da dupla. A partir dos dados coletados foi construída a história clínica do bebê. Cada caso foi analisado de forma individual a partir de sete eixos norteadores, depois foram comparados entre si, a partir da premissa metodológica da Síntese dos Casos Cruzados. Constatou-se que a vivência de internação da mãe e do bebê em uma UTIN interfere negativamente na separação da díade mãe-bebê e nos sentimentos vivenciados pelas mães.
\end{abstract}

Palavras-chave: Bebê, prematuridade, Neonatologia, vínculo mãe-bebê, Psicologia Clínica.

\section{Mothers and Premature Infants Experiences during Neonatal Hospitalization}

\begin{abstract}
The significant increase in births of premature babies in Brazil, the leading cause of death up to 28 days old baby, has worried the different health professionals. Given this reality it was investigated how mothers and premature babies experience the hospitalization in a Neonatal Intensive Care Unit in a hospital interior of Rio Grande do Sul This is a qualitative research design with case studies multiple. Three
\end{abstract}

Endereço para correspondência: Rua Senador Pinheiro, 304 - Passo Fundo, RS, Brasil 99070-220. E-mail: denice.bortolin@imed.edu.br 
premature babies born under 37 weeks and weighing less than 2,500 kg weight, of both genders, who required to remain in attendance at the Neonatal Intensive Care Unit (NICU) between the first month of life, and their mothers participated. The instruments were semi-structured interview; medical records of babies and observation of double sessions. From the collected data was constructed medical history of the baby. Each case was analyzed individually from seven guiding principles, were then compared, from the methodological premise of Synthesis Affairs Crusaders. It was found that the experiences of hospitalization of the mother and baby in a NICU impairs the separation of the mother-infant dyad and the feelings experienced by mothers.

Keywords: Baby, prematurity, Neonatology, mother-baby bond, Clinical Psychology.

\section{Las experiencias de las Madres y los Bebés Prematuros durante la Hospitalización Neonatal}

\section{Resumen}

El aumento significativo de nacimientos prematuros en Brasil, la principal causa de muerte hasta los 28 días después de su nacimiento, ha preocupado a los diferentes profesionales de la salud. Ante esta realidad investigó cómo las madres y los bebés prematuros experiencia hospitalización en la Unidad de Cuidados Intensivos Neonatales, en un Hospital de Interior de Río Grande do Sul. Se trata de una investigación cualitativa con estudios de caso de diseño múltiple. Los participantes fueron tres bebés prematuros nacidos con menos de 37 semanas y un peso de menos de $2.500 \mathrm{~kg}$, de ambos sexos, que necesitaban para mantenerse en la atención en la Unidad de Cuidados Intensivos Neonatales (UCIN) entre el primer mes de vida, y sus madres. Los instrumentos fueron entrevistas semi-estructuradas; historias clínicas de los bebés y la observación de las sesiones dobles. Los datos recogidos se construyó la historia clínica del bebé. Cada caso fue analizado individualmente de siete principios rectores, a continuación, se compararon, de la premisa Resumen metodológica de los casos de los cruzados. Se encontró que las experiencias de hospital de la madre y el bebé en un impacto negativo UCIN en la separación madre-hijo de la díada y sentimientos experimentados por las madres.

Palabras clave: Bebé, prematuro, Neonatología, vinculación madre-hijo, Psicología Clínica.

$\mathrm{O}$ aumento de nascimentos prematuros no Brasil, constatado nos últimos anos (Duarte, Santos, Silva, Oliveira, \& Sampaio, 2010), tem se tornado um fator importante para ampliar e aprofundar os estudos em torno deste tema, enfatizando e conhecendo as particularidades de uma internação neonatal, bem como os riscos e os cuidados destinados a mães e bebês, oferecendo um olhar diferenciado que vise à qualidade e à melhoria do desenvolvimento do bebê prematuro.

Para a Organização Mundial da Saúde, todo bebê que nasce com menos de 37 semanas e com até $2,500 \mathrm{~kg}$ é considerado prematuro ou pré-termo. Os bebês que nascem entre 32 e 35 semanas de gestação são considerados bebês de risco, e os que nascem antes de 32 semanas são considerados de alto risco e com chances reduzidas de sobrevivência (Vidal, 2011). Conforme dados da Organização Mundial da Saúde (Portal Brasil, 2012), o Brasil está entre os 10 países com maiores índices de nascimentos prematuros: a cada 117 partos, um deles é prematuro. A prevalência de partos de crianças prematuras é de 11,7\% em relação a todos os partos realizados no País, e esse percentual coloca o Brasil no mesmo patamar de países de baixa renda, onde a prevalência é de $11,8 \%$ segundo dados Nações Unidas para a Infância (Fundo das Nações Unidas para a Infância [UNICEF] - Brasil, s.d.). Constata-se que bebês prematuros com baixo peso em relação a sua idade gestacional apresentam um maior risco de morte do que bebês prematuros nascidos com peso apropriado a sua idade de gestação (Mussen, Conger, \& Kagan, 2001) e, por ainda não 
apresentarem uma maturidade ideal, são mais vulneráveis a doenças, sendo uma das suas principais dificuldades a respiração.

O nascimento prematuro, não raro, está associado à hospitalização do bebê, devido aos problemas de saúde que este pode apresentar (Shaffer, 2005). A hospitalização pode representar para os pais e para a criança um período complicado e angustiante, pois a relação e os cuidados iniciais que poderiam ocorrer entre eles de maneira natural são dificultados no ambiente da Unidade de Tratamento Intensivo Neonatal (UTIN) e pelos procedimentos que o bebê necessita durante a internação (Duarte et al., 2010).

A UTIN é definida como um local preparado para receber bebês de alto risco e tem como objetivo prestar um cuidado assistencial, através de uma equipe qualificada para dar suporte e atendimento às necessidades do bebê, garantindo maiores possibilidades de sobrevivência (Pedroso \& Bousso, 2003). Porém, apesar de ser um lugar fundamental para a sobrevivência dos bebês prematuros, pode tornar-se um ambiente hostil para os que não estão adaptados a ele, pois as luzes são fortes e contínuas, a temperatura é variada e os bebês precisam ser submetidos a vários procedimentos e situações que podem interromper seu ciclo de sono, gerando-lhes incômodo e dor (Reichert, Lins, \& Collet, 2007, apud Nascimento, 2012). Esta rotina a que os bebês são submetidos, além de influenciar no seu desenvolvimento, torna-se para os pais um processo angustiante, e muitas vezes faz com que se sintam inseguros, devido à falta de conhecimento em relação ao quadro clínico do filho (Oliveira, Veronez, Higarashi, \& Corrêa, 2013).

Além da angústia e insegurança, ao visitarem o filho prematuro, os pais podem sentir certo estranhamento, uma vez que estão presos ao bebê imaginário, idealizado durante a gravidez e geralmente não condizente com o bebê real, que pode se apresentar pálido, magro e frágil. Para a mãe, esta situação pode se tornar ainda mais difícil, porque, em muitos casos, ela não está preparada emocionalmente e não se encontra fisicamente capaz de interagir com o filho naquele momento (Klaus \& Kennel, 1993; Scochi et al., 2003).
Rodholm e Larsson (1979, apud Scortegagna et al., 2005) salientam a importância do contato inicial da mãe com o seu bebê e observam que mães autorizadas a tocarem seus filhos prematuros proporcionavam com as palmas das mãos toques envolventes que se transformavam em massagens e carícias. Porém, muitas vezes, este contato inicial não é possível, pois inicia-se, geralmente, com o bebê na incubadora, dificultando o toque materno, permitindo às mães que toquem seus filhos apenas com as pontas dos dedos. A incubadora ainda dificulta a interação do olhar entre mãe e filho e, desta forma, as respostas aos cuidados e gratificações que este pode viabilizar (Winnicott, 1975).

Analisando estes fatores, percebe-se que a necessidade da internação em UTIN do bebê prematuro pode prejudicar o contato inicial entre os pais e o seu filho. No entanto, a participação da mãe durante a internação do bebê pré-termo é fundamental para o vínculo de ambos e, se a saúde, tanto do bebê quanto da mãe, permitir, esta aproximação deve ser estimulada e ampliada. Quando a criança nasce prematuramente e precisa ficar hospitalizada, fatores como o período de tempo em que ficou internada, procedimentos médicos aos quais precisou ser submetida e cuidados que recebeu durante este período, são relevantes para avaliar o seu desenvolvimento (Padovani, Linhares, Carvalho, Duarte, \& Martinez, 2004).

Constata-se que, apesar da possibilidade do parto prematuro influenciar em áreas significativas da vida do bebê, as consequências decorrentes da prematuridade no seu desenvolvimento, negativas ou não, poderão ser percebidas em longo prazo e dependerão do tempo de nascimento, peso ao nascer, cuidados pós-natal e influências ambientais a que o bebê estará exposto na sua infância (Mussen et al., 2001).

De acordo com Winnicott (2012), ao nascer, o bebê começa a formar a base de sua personalidade e individualidade, descobrindo a própria importância. Este estágio contribui para a sua evolução emocional e ocorre de maneira estável e sadia, se sua base foi constituída por meio de uma experiência primária de egoísmo. O egoísmo primário descrito pelo autor significa a expe- 
riência de uma assistência materna adequada, ou seja, o bebê precisa sentir que possui a mãe, que exerce controle sobre ela e que esta foi criada para aquele momento. Deste modo, a mãe atende em tempo integral às solicitações do bebê, identificando e interpretando suas manifestações (Fulgencio, 2007).

A partir destes estudos, constata-se que o nascimento prematuro pode afetar as primeiras vivências de mães e bebês, posto que a mãe, frente à internação do filho após o parto, pode ser impossibilitada de oferecer-lhe os cuidados primários e fundamentais para o seu desenvolvimento e criação da relação vincular com este. E, para o bebê, as representações são constituídas de acordo com as experiências ambientais e as relações vividas no contexto da hospitalização.

Além da prematuridade influenciar nos cuidados maternos com o filho, afeta a mãe e, consequentemente, a interação com o seu bebê que fica internado enquanto a mãe obriga-se a ir para casa sozinha, sendo acometida por um forte sentimento de frustração, revivendo fantasias, como a de castração, configuradas na representação de não ter conseguido concluir a gestação e ter gerado um bebê inacabado. Mas ambos os pais podem ser dominados pela culpa, ao se sentirem responsáveis pela prematuridade, fortalecendo a ideia de que não são capazes de serem pais (Lebovici, 1987).

A partir disso, a mãe pode ser invadida por sentimentos de inferioridade, sendo atingida profundamente em sua autoestima, nas suas capacidades maternas e no seu papel feminino de ter gerado um bebê saudável. Isso porque o nascimento prematuro é sentido como se uma parte do corpo tivesse sido perdida, tornando-se uma ameaça a sua integridade corporal, reforçando as fantasias da mãe em relação ao seu interior, sentido como inferior e perigoso (Brazelton \& Cramer, 1992).

Durante a gravidez, os pais sustentam o ideal de levar o filho para casa após o nascimento e, quando são informados que este precisará ficar hospitalizado em uma UTIN, sentimentos de aflição e desespero são reforçados pelo medo e a culpa de deixar o filho internado (Oliveira et al., 2013). Neste mesmo sentido, Winnicott (2006) afirma que as fantasias e representações acerca do bebê esperado iniciam-se ainda antes e durante a gravidez. Este bebê passa a ser idealizado pelos pais e, pelas suas fantasias, será um bebê dono das melhores qualidades, dotado de onipotência e perfeição (Debray, 1988).

Com o nascimento do bebê prematuro, necessita-se que os pais passem por um processo de luto deste filho idealizado, sendo que esta situação poderá acarretar dificuldades de vinculação com o mesmo (Brazelton, 1988). Debray (1988) postula que, além da separação física e prematura do bebê e da mãe através do parto, acontece uma segunda separação, já que o bebê necessita ficar em outro local do hospital, geralmente, em uma incubadora. Esta separação representa mais uma barreira para a interação e o vínculo inicial da mãe com o bebê, e este, por sua vez, também não consegue responder de maneira satisfatória aos estímulos dos pais, pois, no processo de hospitalização, o seu desenvolvimento se dá a partir da influência e mediação da equipe da UTIN (Mathelin, 1999).

Dessa forma, a equipe cuidadora deve estar preparada tanto para o auxiliar o bebê quanto a mãe, entendendo as diversas manifestações de sentimentos maternos que relacionam-se ao período de hospitalização do filho, porque as mães, apesar do medo da perda, precisam acreditar na recuperação de seus recém-nascidos. Esta conduta fica explícita quando as mães manifestam sua religiosidade como fonte de apoio e consolo em um momento carregado de medos e angústia (Fraga \& Pedro, 2004).

A prematuridade e a internação que se segue após o parto tornam-se uma fase ansiogênica e angustiante para a tríade mãe, pai e bebê. A separação entre eles pode apresentar consequências, devido à falha de muitos processos fundamentais que deveriam acontecer no início da vida da criança. Assim, a partir destas considerações, o objetivo desta pesquisa foi investigar como mães e bebês prematuros vivenciam o período de internação em uma Unidade de Tratamento Intensivo Neonatal, em um hospital do interior do Rio Grande do Sul. Diante de todas as situações que mães e bebês prematuros vivenciam durante o período de internação neonatal, pretende-se 
aprofundar a compreensão acerca do tema, para que, em caráter preventivo, seja possível refletir sobre intervenções que visem a um melhor desenvolvimento do bebê prematuro durante a sua internação.

\section{Método}

\section{Delineamento}

Trata-se de uma pesquisa qualitativa, com delineamento de estudos de casos múltiplos, que visa registrar, analisar, classificar e interpretar os fatos, sem que haja uma interferência por parte do pesquisador (Diedrich, 2009). De acordo com Emidio (2008), a pesquisa qualitativa possibilita um olhar diferenciado ao objeto estudado, já que valoriza a subjetividade dos sujeitos e das relações estabelecidas. Com isso, torna-se mais minuciosa, fornecendo uma riqueza de detalhes, permitindo a qualidade do conteúdo e das informações obtidas.

\section{Participantes}

Participaram da pesquisa três bebês prematuros que nasceram com menos de 37 semanas e com peso inferior a $2.500 \mathrm{~kg}$, internados em um mesmo hospital no interior do estado do Rio Grande do Sul, de ambos os gêneros, que necessitaram permanecer em atendimento na UTIN entre o primeiro e o terceiro mês de vida, e suas respectivas mães. A Tabela 1 contém a descrição detalhada dos participantes.

Tabela 1

Participantes

\begin{tabular}{cccccc}
\hline Caso & Mãe/Idade & Bebê/IG ao nascer & $\begin{array}{c}\text { Peso do Bebê ao } \\
\text { nascer }\end{array}$ & $\begin{array}{c}\text { Cuidados } \\
\text { ao nascer }\end{array}$ & $\begin{array}{c}\text { Tempo internação } \\
\text { até pesquisa }\end{array}$ \\
\hline 1 & Janete/37 & Carla/30 semanas & $1,535 \mathrm{~kg}$ & Ventilação mecânica & 60 dias \\
2 & Luana/26 & Maria/30 semanas & $1,845 \mathrm{~kg}$ & $\begin{array}{c}\text { Aquecida, medidas } \\
\text { antropométricas e } \\
\text { medicações }\end{array}$ & 15 dias \\
3 & Marta/45 & Larissa/32 & $1,095 \mathrm{~kg}$ & Nenhum & 59 dias \\
\hline
\end{tabular}

\section{Instrumentos}

A presente pesquisa utilizou os seguintes instrumentos:

Entrevista Semiestruturada. Composta por questões abertas (Santos \& Candeloro, 2006), foi feita com as mães e teve como objetivo identificar aspectos da vivência das mães na UTIN, bem como da relação com o bebê e com a equipe de profissionais da UTIN. Este instrumento permitiu que as mães se expressassem livremente sobre a angústia e as dificuldades que enfrentaram em relação à prematuridade do filho e hospitalização que se seguiu após o parto.

Prontuário Médico dos Bebês. Foram levantadas informações a respeito do bebê quanto à ocorrência de fatores clínicos no nascimento $\mathrm{e}$ durante a internação, como relato de asfixia no momento do parto, necessidade de reanimação
(Teste de Apgar), uso de oxigênio por período prolongado, entre outros dados considerados significativos para compreender a vivência precoce do bebê durante sua internação.

Sessões de Observação da Dupla. Utilizou-se o método da observação, a fim de descrever, interpretar e analisar os fatos para a futura integração dos dados e uma compreensão qualitativa. O método observacional, nesta pesquisa, seguiu o caráter de uma observação não participante, na qual o pesquisador esteve em contato com o fenômeno estudado, porém, não interferiu nos acontecimentos, permaneceu observando de forma ordenada e dirigida, mas não participou da situação (Marconi \& Lakatos, 2006).

A partir dos dados coletados no prontuário médico do bebê e com a entrevista semiestruturada realizada com as suas mães, foi construída 
a história clínica do bebê, de acordo com Meio (1999). Neste estudo, foram investigados dados como identificação do bebê, fatores clínicos do nascimento e durante a internação, como data e peso de nascimento, gênero, idade gestacional, gestação única ou gemelar, parto cesárea ou vaginal, manobras em sala de parto, horas de internação e dados demográficos (genitores, estado civil, escolaridade, profissão, número de gestações, renda familiar, dentre outros).

\section{Procedimentos de Coleta e Análise dos Dados}

A coleta de dados ocorreu no período de agosto e setembro de 2013, após a aprovação do Comitê de Ética em Pesquisa (CEP) da Faculdade Meridional, através do Parecer Consubstanciado $\mathrm{n}^{\circ} 348264$ e da aprovação do local para a realização desta pesquisa. Inicialmente, realizou-se o primeiro contato com as mães dos bebês, no próprio Hospital, com a finalidade de explicar e clarear dúvidas quanto a sua participação e a do filho na pesquisa. Após este contato inicial, foi lido e assinado o Termo de Consentimento Livre e Esclarecido (TCLE), para a realização da entrevista semiestruturada, que ocorreu em um segundo momento e, posteriormente, foi feita a observação dos bebês na UTIN.

A observação foi realizada em cinco dias. No primeiro e segundo dias, foram destinadas um total de seis horas diárias, no período da manhã e tarde, a fim de observar de forma geral os aspectos e a rotina da UTIN. Posteriormente, respeitando a ordem de internação, foi estipulado um dia para que cada bebê pudesse ser observado. A observação de cada bebê participante totalizou sete horas diárias, incluindo a observação individual em cada turno e as visitas maternas que ocorriam durante trinta minutos à tarde e à noite. No método de observação, foi utilizado um diário de campo, onde a pesquisadora anotou tudo que foi possível observar sobre o bebê, sua mãe, a relação entre a díade, ambiente físico e equipe técnica de trabalho na UTIN. Além da entrevista semiestruturada e das observações realizadas na UTIN, analisou-se o prontuário médico do bebê, a fim de construir sua história clínica, agregando às informações obtidas através da entrevista com as mães.

A análise dos dados encontrados por meio da observação, prontuário médico e entrevista com as mães dos bebês foi realizada com base na sua apreciação e interpretação. Tais instrumentos foram utilizados para construir cada um dos casos, individualmente, procurando suas particularidades. Cada caso foi analisado a partir de sete eixos norteadores, que são

1. Expectativas maternas sobre o bebê e a maternidade;

2. Sentimentos maternos sobre a prematuridade e o bebê;

3. Exercício da maternidade;

4. Relação mãe e bebê;

5. Relação com a equipe e com o ambiente da UTIN;

6. Vivências do bebê; e,

7. Expectativas maternas em relação ao futuro. Após a análise individual, os casos foram comparados entre si, a partir da premissa metodológica da Síntese dos Casos Cruzados (Yin, 2005).

\section{Resultados e Discussão}

A pesquisa foi realizada na UTIN de um hospital público/privado no interior do Rio Grande do Sul. O ambiente físico deste local é composto por uma sala única, dividida em nove leitos, onde os bebês internados permanecem lado a lado, alguns em incubadoras e outros em berços. A UTIN é um ambiente com temperatura regulada, sons e movimentos contínuos. $\mathrm{Na}$ maioria das observações, o ambiente permanecia com luzes fortes e, na rotina da tarde, após a visita dos familiares, parte destas luzes eram desligadas, permanecendo apenas a iluminação necessária para o monitoramento dos bebês. Neste momento, ouvia-se uma canção de ninar, tornando o ambiente mais calmo e tranquilizador para os bebês. Contudo, na maior parte das observações, pode-se constatar que a UTIN observada é um ambiente que contém muitos barulhos, incluindo aparelhos, toque de telefones e conversas constantes. 
A equipe cuidadora observada é composta por cinco enfermeiras. Cada profissional da equipe é responsável por mais de um bebê, que é monitorado constantemente, verificando a medicação, sinais vitais, alimentação e higiene. O contato tátil da equipe com os bebês se dá somente através da troca de fraldas e procedimentos médicos, sendo que estes são segurados apenas quando estimulados à mamadeira, permanecendo o restante do tempo em seus leitos.

\section{Caso 1: Janete e Carla}

Janete, 37 anos, casada, do lar, é mãe do bebê Carla, que encontrava-se hospitalizada na UTIN observada desde o seu nascimento, totalizando 60 dias de internação até o término desta pesquisa. Janete contou que a gravidez de Carla foi planejada e ficou muito feliz quando soube que estava grávida, pois tinha somente uma filha, que já estava com dez anos de idade. As tentativas para engravidar novamente duraram um ano e meio até o momento em que recebeu a notícia de que estava grávida de Carla, sentindo-se "realizada [sic]" com a gravidez. Janete relatou que, na gestação de sua filha mais velha, tudo correu dentro da normalidade até que, com trinta e sete semanas, começou a ter dilatações, que resultou no nascimento da criança por parto natural. $\mathrm{Na}$ gestação de Carla, ela disse que também estava tudo normal e que fazia o acompanhamento de sua gravidez, realizando consultas pré-natais dentro do prazo. Com 30 semanas de gestação, Janete, sentindo-se muito bem, foi a uma consulta de rotina e o médico afirmou que ela estava com dilatações para o parto e que já não tinha como reverter o processo. Imediatamente, foi preparada e Carla nasceu de parto natural pesando $1,535 \mathrm{~kg}$, apresentando choro em forma de gemência e Apgar 9 no primeiro e quinto minuto, porém, nos momentos seguintes, necessitou de ventilação mecânica. Em uma hora, foi transportada da sua cidade até a UTIN em incubadora e com respirador, onde a equipe recebeu a bebê ativa, com extremidades frias e pele apresentando hematomas devido ao manuseio após o parto. Carla apresentou membrana hialina, cianose e icterícia, necessitando de incubadora e fototerapia durante sua internação.

\section{Caso 2: Luana e Maria}

Luana, 26 anos, estudante, casada, é mãe do bebê Maria, hospitalizada desde o momento do seu nascimento, totalizando 15 dias de internação até o término desta pesquisa. Luana contou que, além de Maria, que está internada, é mãe de mais uma menina de sete anos. Ela relatou que, na gestação anterior a de Maria, houve intercorrências, como ameaças de aborto e descolamento de placenta, sendo que sua filha mais velha nasceu prematuramente com trinta e seis semanas, porém, sem a necessidade de internação. A gravidez de Maria foi planejada pelo casal, pois tinham somente uma filha e esta sempre cobrava dos pais um irmão. Luana engravidou no quarto mês de tentativa e fazia constantes visitas ao médico e um pré- natal regulado. Em uma de suas consultas, descobriu que sua gestação era gemelar monocoriônica e que esperava duas meninas. Foi informada sobre o risco de ter os bebês prematuramente, mas nunca imaginou que isso realmente pudesse acontecer, pois, em suas consultas pré-natais, constatava-se que a sua gravidez e o desenvolvimento dos bebês ocorria dentro da normalidade. Com 30 semanas de gestação, Luana visitou o médico para uma consulta de rotina e foi verificado, através de uma ultrassonografia, que um dos bebês havia sofrido morte intrauterina, há, mais ou menos, 15 dias, oferecendo risco de infecções ao bebê que permanecia vivo. Com isso, era necessário realizar um parto de emergência, a fim de salvar o bebê sobrevivente. Luana viajou para fazer o parto até o hospital que dispõe de um leito em UTIN. Maria nasceu de parto cesárea, pesando $1,845 \mathrm{~kg}$, apresentando choro forte e Apgar 8 e 9 no primeiro e quinto minuto, mostrando-se ativa e com respiração espontânea. Chegou à unidade cianótica e com extremidades frias, onde foi aquecida, recebeu as medidas antropométricas e as medicações necessárias. Durante o período de sua internação, apresentou membrana hialina e icterícia, necessitando de incubadora e fototerapia.

\section{Caso 3: Marta e Larissa}

Marta, 45 anos, casada, secretária, é mãe do bebê Larissa, hospitalizada na UTIN desde o 
momento de seu nascimento, totalizando 59 dias de internação até o término desta pesquisa. Marta contou que sempre quis ter um filho, porém, seu ex-marido, em virtude de problemas com a saúde, não podia. Após o fim do seu primeiro casamento, ela casou-se novamente, planejando ter um filho. Marta teve uma única gestação e fez o tratamento indicado para poder engravidar, bem como todo pré-natal necessário durante a gestação, pois possuí trombofilia, que poderia se tornar um fator de risco para a sua gravidez. Contou que sua gestação ocorria dentro da normalidade e que sempre se sentiu bem. Em um dia comum, no seu trabalho, Marta começou a sentir contrações e foi até o hospital, onde se constatou que o bebê iria nascer, mas, como ela não tinha dilatação suficiente para um parto natural, foi necessário fazer um parto cesárea. Larissa nasceu com 32 semanas de gestação, pesando $1,095 \mathrm{~kg}$, apresentando restrição de crescimento intrauterino, respiração espontânea, choro forte e Apgar 8 e 9 no primeiro e quinto minuto. Chegou à UTIN ativa, aquecida, rosada e aspirada. Durante o período de internação, apresentou cianose, membrana hialina e icterícia, necessitando de incubadora e fototerapia.

\section{Síntese dos Casos Cruzados}

No Eixo I, denominado "Expectativas maternas sobre o bebê e a maternidade", foram analisadas as vivências maternas que se referem às expectativas que alimentavam em relação ao bebê, especialmente antes da internação neonatal. Winnicott (2006) afirma que as fantasias e representações acerca do bebê esperado acompanham toda a gravidez e inicia-se antes mesmo do bebê ser concebido. Este bebê passa a ser idealizado pelos pais, como um bebê dono das melhores qualidades, dotado de onipotência e perfeição (Debray, 1988). Nas falas de Marta, observa-se as fantasias e idealizações, ao dizer o que esperava da sua gestação e do seu bebê: "eu imaginava que tudo ia dar certo, que ela ia ser muito saudável, nunca pensei que pudesse ter a Larissa prematura", " nunca imaginei que ela ia nascer de 32 semanas". Sendo assim, é necessário passar por um processo de luto, tanto de uma gravidez idealizada quanto do bebê imaginário ligado ao retrato mental que a mãe criou para ele, que pode não ser condizente com a imagem do bebê real, que, geralmente, se apresenta pálido, magro e frágil (Klaus \& Kennel, 1993).

Além das fantasias criadas acerca do bebê, durante a gravidez, os pais sustentam o ideal de levá-lo para casa após o nascimento e, quando são informados que ele precisará ficar hospitalizado em uma UTIN, sentimentos de aflição e desespero são reforçados pelo medo e a culpa de deixá-lo internado (Oliveira et al., 2013). Estes sentimentos podem ser evidenciados através das falas das participantes: "sabia que ela estaria em boas mãos, mas saber que ficaríamos separadas deu uma agonia, medo do que ia acontecer com ela" (Marta); "vem um monte de perguntas na cabeça, o que será daqui pra frente, como vou deixar ela aqui sozinha?" (Janete). A aflição e o medo das mães em separar-se dos filhos, quando são obrigadas a irem para suas casas sozinhas, sem levá-los, começam a gerar dúvidas que reforçam a impotência frente à situação de hospitalização em que o filho se encontra.

Já o Eixo II, "Sentimentos maternos sobre a prematuridade e o bebê", inclui os sentimentos das mães em relação ao bebê e à situação de prematuridade. Através da análise das entrevistas com as mães participantes, foi possível constatar os sentimentos vivenciados por estas durante o período de hospitalização do filho prematuro. Percebe-se que todas as mães vivenciaram sentimentos de culpa em relação à prematuridade do filho, como pode constatar-se nas falas das participantes: "no dia que eu tive ela, eu caminhei bastante porque o posto de saúde era longe, não sei se pode ter ajudado ela nascer" (Janete) e

foi uma surpresa, o médico dizia que estava tudo bem, fiquei triste, senti revolta, tive medo que a outra bebê também morresse, não foi um momento de alegria, pois eu sabia que uma delas estava morta, ficava me perguntando o que eu fiz pra merecer isso? (Luana)

A culpa expressada pelas mães parece estar configurada na busca de alguma situação ou acontecimento concreto que explique de forma racional o nascimento prematuro. Ou seja, elas 
entendem que podem ter feito algo errado e que isso ocasionou o parto prematuro, tornando-as merecedoras deste episódio. Ao sentir-se responsável pela prematuridade, a mãe revive fantasias configuradas na representação de não ter conseguido concluir a gestação e ter gerado um bebê inacabado, fortalecendo a culpa e a ideia de que não é capaz de ser mãe (Lebovici, 1987).

Os sentimentos vivenciados pelas mães, em relação à prematuridade do filho, também revelam angústia, medo e estranhamento ao olharem seus bebês pela primeira vez, como percebe-se na fala de Janete: "chorei muito, tão pequena, parecia que não ia sobreviver", e Marta: "era a mais pequena que tinha ali na UTIN, nunca tinha visto um nenê tão pequenininho como ela". Tais sentimentos relacionam-se ao fato de que as mães precisam adaptar-se à imagem do bebê real, que, muitas vezes, não se ajusta à imagem fantasiada por elas, criada mesmo antes da gestação, pois as mães participantes planejaram a sua gravidez, desejando a criança.

O terceiro eixo, denominado "Exercício da maternidade", refere-se às vivências das mães e suas tentativas de exercerem seu papel materno durante a internação do bebê na UTIN, bem como uma tentativa de refletir sobre o impacto para o bebê dos cuidados que recebe durante a internação. A impossibilidade da mãe em oferecer seus cuidados ao bebê, durante o período em que ele permanece internado, parece atingir a sua autoestima, visto que ela não consegue desempenhar seu papel materno. É possível identificar estes aspectos no discurso de Luana: "fiquei muito triste, olhar as outras com os seus bebês indo embora e ter que deixar o meu aqui" e Marta, quando diz que: "dá uma sensação de vazio", "quero cuidar dela, as enfermeiras dizem: olha Larissa, essa ai é tua mãe de verdade, nós somos mães só do coração".

A tristeza de Luana em não poder sair com o seu bebê da maternidade, como as outras mães que levam os seus bebês para casa, parece decorrer da impossibilidade de exercer o que acredita ser seu papel feminino e materno de gerar um bebê saudável. O querer cuidar e, ao mesmo tempo, ter que deixar o bebê aos cuidados da equipe da UTIN faz com que a mãe seja acometida por sentimentos de inferioridade e impotência, fortalecidos pela incapacidade de desempenhar suas funções maternas. O sentimento de vazio expressado por Marta, ao separar-se da filha, representa a perda de algo que lhe pertencia e que lhe foi tirado, deixando-a vazia. Neste sentido, Brazelton e Cramer (1992) afirmam que o nascimento prematuro é sentido como se uma parte do corpo tivesse sido perdida, representando uma ameaça a sua integridade corporal, reforçando as fantasias da mãe em relação ao seu interior, sentido como inferior e perigoso.

Neste mesmo contexto, percebe-se ainda que a incapacidade e a impotência em desempenhar a função materna se intensificam quando o bebê necessariamente é separado da mãe através dos equipamentos, como a incubadora, dificultando a relação e o contato entre estes. Debray (1988) postula que, além da separação física e prematura do bebê e da mãe através do parto, a permanência do bebê na UTIN e na incubadora representa mais uma barreira para a interação e o vínculo inicial da mãe com o bebê, haja visto que, como dito anteriormente, o equipamento possui apenas uma escotilha por onde os bebês são alimentados, limpos e trocados, a qual é pequena demais para possibilitar o carinho e o contato dos pais com o filho de modo natural (Shaffer, 2005).

Segundo Lara e Kind (2014), o ambiente da UTI Neonatal, seus equipamentos, tecnologia, procedimentos e protocolos, bem como a linguagem técnica da equipe, podem produzir diferentes efeitos sobre o exercício da maternidade. Se, por um lado, pode se produzir uma relação de confiança entre família e equipe, por outro as mães podem vivenciar a experiência de ser uma mãe substituta para o próprio filho, desencadeando sentimentos de rivalidade e exacerbando a sensação de menos valia, incompetência e fracasso.

Winnicott (2000) observa que os cuidados oferecidos ao bebê não podem limitar-se a um ato mecânico para satisfazer suas necessidades fisiológicas, e exigem uma empatia extremamente sensível por parte do cuidador, que deve considerar a sensibilidade dérmica do bebê, o tato, a temperatura, a sensibilidade auditiva e visual. 
As negligências neste processo podem ocasionar sentimentos de desintegração e aniquilamento, pois o recém-nascido encontra-se em um estado de dependência absoluta, necessitando que o outro se doe totalmente aos seus cuidados autoconservativos e afetivos, fazendo todas as ligações necessárias entre ele e seu mundo, para que, posteriormente, saia deste estado de total dependência para uma dependência relativa e, mais tarde, rume à independência (Winnicott, 2006).

Além disso, a situação de internação do bebê muitas vezes obriga os pais, e em especial a mãe, a lidar com a mediação da tecnologia e do saber médico sobre os cuidados maternos. Assim, é comum que o discurso médico ocupe o lugar das conjecturas maternas sobre o bebê e suas necessidades, prejudicando o investimento materno e o reconhecimento do bebê como seu (Ferrari \& Donelli, 2010).

O Eixo IV, "Relação mãe e bebê", aborda as relações que se estabelecem entre mãe e bebê no ambiente do UTIN. Percebeu-se que as mães permaneciam ao lado da incubadora esperando qualquer reação do bebê em relação ao seu toque, sua voz e seu olhar. No caso da bebê Maria, percebe-se que a mãe é acometida por intensa ansiedade, no desejo de tirar a filha dos equipamentos e cuidá-la, na tentativa de sentir-se a verdadeira mãe. A ansiedade e a busca pela reação do bebê a sua presença acabam atrapalhando a sua vinculação e interação com a filha, uma vez que a mãe proporciona toques rápidos e intensos em todo o corpo do bebê e chama-o com um tom de voz relativamente alto em relação às outras mães. O bebê responde chorando e com sinais de agitação, como se não estivesse suportando os estímulos recebidos por parte da mãe.

Ressalta-se que a maneira de tocar o bebê influencia nas suas reações, porque a sensibilidade tátil é o primeiro sistema sensorial a se desenvolver. A delicadeza do toque, o toque parado ou de maneira firme podem ocasionar benefícios para o bebê prematuro (Pacheco, Silva, Lioi, \& Rodrigues, 2012). Este toque é percebido nas visitas realizadas pela mãe de Larissa, quando esta parece acalmar-se com as leves batidas que a mãe dá sobre o seu corpo, alternado com um tom de voz suave e tranquilizador. Da mesma forma, ao amamentar sua filha, durante as visitas, Janete faz carícias suaves, estimulando e fazendo com que o bebê reaja de forma satisfatória, realizando movimentos de sucção no seio materno.

Sabe-se que, em condições ideias, a mãe é capaz de estabelecer com o bebê um relacionamento simbiótico, dispondo de um preparo biológico para recebê-lo e adaptar-se as suas necessidades de modo singular, assim como é capaz de desenvolver um estado de preocupação materna primária, pelo qual possibilita ao bebê condições para o seu desenvolvimento psíquico. Além disso, através do holding, a mãe, além de satisfazer as necessidades fisiológicas do bebê, como trocar, limpar e amamentar, também satisfaz as necessidades afetivas deste, ao embalar, acariciar, olhar e tocar de forma apropriada (Winnicott, 2000, 2006).

Considerando que este processo é prejudicado pela separação da díade, em decorrência da hospitalização do bebê prematuro, estes cuidados ficam a cargo da equipe da UTIN, que, naturalmente, não dispõe de um preparo biológico ou um estado de preocupação materna primária, ficando impedida de oferecer a estes bebês a satisfação de suas necessidades afetivas, acabando por priorizar as tarefas de cuidar da medicação e atender às necessidades básicas, como alimentação e higiene. Com isso, muitas vezes, este processo torna-se mecânico, sem o envolvimento mais profundo do toque, da carícia e do olhar

No Eixo V, "Relação com a equipe e com o ambiente da UTIN", foram analisadas as vivências maternas e também do bebê em relação à interação com a equipe de saúde e com o ambiente da UTIN. Os bebês são monitorados durante todo o tempo pela equipe cuidadora integrada por cinco enfermeiras. Cada enfermeira é responsável por mais de um bebê, verificando a medicação, sinais vitais, alimentação e higiene. Ao desempenhar suas tarefas, cada enfermeira é impossibilitada de atender prontamente às necessidades de cada bebê, já que precisa cuidar de vários ao mesmo tempo. Considerando que, no período de hospitalização do bebê prematuro, é a equipe da UTIN a responsável por desempenhar as funções cuidadoras, é possível evidenciar as falhas envolvidas neste processo. 
Os bebês internados permanecem em tempo integral em seus leitos, sendo que apenas o bebê estimulado na mamadeira era segurado pela enfermeira responsável durante o tempo da alimentação e no horário das visitas familiares, e apenas a bebê Carla era entregue à mãe para a amamentação. A partir destes dados, constata-se que os bebês hospitalizados pouco podem desfrutar do afeto que poderiam receber através de um maior contato com o seu cuidador. Sendo assim, percebe-se que, na UTIN, somente são satisfeitas as necessidades básicas de cada bebê, como a alimentação e a higiene necessária, porém, as necessidades afetivas dos bebês internados permanecem à mercê dos poucos minutos que a mãe pode vê-lo e acariciá-lo, na maioria dos casos, através da incubadora, que torna-se mais um obstáculo na busca deste contato.

A partir da observação relacionada à equipe de enfermagem, nota-se que esta se esforça para tornar o ambiente mais tranquilizador aos bebês internados, pois, durante a tarde, algumas luzes da UTIN são desligadas para criar um ambiente com uma iluminação mais amena e escuta-se uma canção de ninar posta pela própria equipe. Porém, na maior parte da observação, pode-se constatar que o ambiente da UTIN contém muitos barulhos, incluindo equipamentos, toque de telefones e conversas constantes, interferindo no ciclo de sono de cada bebê, por isso, alguns acordavam sobressaltados, ao ouvirem sons mais altos que o habitual. Sabe-se que a UTIN é um lugar fundamental para a sobrevivência dos bebês prematuros, porém, pode tornar-se um ambiente hostil, em virtude das luzes serem fortes e contínuas, da temperatura ser variada, dos procedimentos a que os bebês são submetidos e das situações que podem interromper o ciclo de sono dos bebês, gerando-lhes incômodo e dor (Reichert et al., 2007, apud Nascimento, 2012).

Essa hostilidade do ambiente facilmente ultrapassa a capacidade de elaboração possível pelo eu ainda incipiente do bebê, configurado esse período como potencialmente traumático para a criança. No início da vida, o bebê ainda não desenvolveu suficientemente condições psíquicas para lidar com as falhas ambientais e, nesse contexto, é fundamental que ele conte com um cuidador ativamente adaptado às suas necessidades, que o proteja das intrusões do mundo externo e minimize a necessidade de o bebê reagir e sair do seu estado de ilusão (Donelli, 2011).

Da mesma forma que o ambiente da UTIN torna-se hostil para o bebê internado, ele também é sentido pela mãe como um ambiente assustador e desagradável. Analisando o discurso de Janete: "chorei muito, tão pequena, parecia que não ia sobreviver e aquele monte de aparelho assusta" e Luana: "eu queria cuidar ela, tirar aqueles aparelhos, olhar o olhinho dela, trocar, dar mamá", percebe-se que a UTIN e os equipamentos necessitados pelo bebê suscitam nas participantes sentimentos de angústia e ansiedade, posto que ocasionam o surgimento de pensamentos relacionados ao medo da perda e que estão diretamente ligados à imagem frágil do bebê e ao uso de um aparato tecnológico para que possa sobreviver. A apropriação que muitas mães fazem do discurso médico que, naquele momento, parece ser a única coisa capaz de garantir a sobrevivência do bebê, pode ser entendido como uma defesa contra a angústia gerada pela separação e pela iminência de morte do filho (Ferrari \& Donelli, 2010).

O Eixo VI, denominado "Vivências do bebê", é uma tentativa de refletir sobre as possíveis vivências emocionais do bebê prematuro, a partir da observação de seu comportamento. $\mathrm{O}$ estado de dependência absoluta em que o bebê se encontra ao nascer faz com que necessite do auxílio integral do seu cuidador, e um dos meios de comunicar ao meio externo o que está sentindo e o que necessita é através do seu choro.

Neste aspecto, um fator importante observado na UTIN relaciona-se à percepção de que os três bebês analisados choram pouco e que este choro somente é ouvido quando alguma necessidade fisiológica precisa ser satisfeita. Sobre isso, é importante ressaltar as considerações de Winnicott (2012), quando se reporta ao choro dos bebês. $\mathrm{O}$ autor afirma que os bebês choram por diversos motivos, cabendo a uma mãe suficientemente boa interpretar este choro que, em muitas ocasiões, representa uma forma do bebê lidar com as próprias dificuldades, significando que busca, através do seu choro, o auxílio do 
cuidador para suportar suas dores, medos, bem como satisfazer suas necessidades. Todavia, quando um bebê não chora ou deixa de chorar, pode significar que este perdeu a esperança em seu cuidador e passou a vivenciar sentimentos de desamparo e desintegração. $\mathrm{O}$ fato dos bebês hospitalizados na UTIN observada chorarem apenas quando necessitam de cuidados fisiológicos pode estar relacionado à sua desesperança quanto aos seus cuidadores em atender suas necessidades afetivas e amenizar as dificuldades encontradas em um meio repleto de diversas perturbações externas, que repercutem na construção da sua subjetividade.

Por último, o Eixo VII, denominado "Expectativas maternas em relação ao futuro", inclui as expectativas das mães em relação aos seus bebês e à própria maternidade após a alta hospitalar. Ao mesmo tempo em que as mães vivenciam sentimentos negativos em relação à prematuridade dos filhos e à hospitalização que se segue após o parto, sentem a necessidade de crer na recuperação destes, buscando uma fonte de apoio na sua religiosidade, que torna-se evidente nas seguintes falas: "eu só pensava em Deus, queria que ficasse tudo bem com ela"; "eu orava muito, sabia que era grave, mas ela veio pra onde tinha recurso, entreguei nas mãos de Deus" (Janete); "faço minhas orações quando estou com ela" (Marta); "creio que Deus fará a sua parte" (Luana). Estas falas evidenciam a manifestação da religião como um auxílio na reabilitação dos seus bebês. Segundo Fraga e Pedro (2004), as mães de recém-nascidos internados em UTIN acreditam ou necessitam crer na melhora de seus filhos, encontrando na religião o consolo e o conforto que precisam para enfrentar um período difícil, no qual o medo da perda está sempre presente.

\section{Considerações finais}

Este estudo teve como objetivo investigar como mães e bebês prematuros vivenciam o período de internação em uma Unidade de Tratamento Intensivo Neonatal, em um hospital do interior do Rio Grande do Sul. Sendo assim, através dos dados obtidos, foi possível eviden- ciar que, apesar da necessidade de internação para a sobrevivência dos bebês prematuros, há, neste contexto, fatores prejudiciais ao desenvolvimento destes, como a separação da díade mãe-bebê e os sentimentos vivenciados pelas mães, como culpa, inferioridade, aflição, angústia, desespero, estranhamento, medo, vazio e impotência, que acabam influenciando na sua relação de interação e vinculação com o filho.

Percebe-se que o desenvolvimento inicial do bebê é afetado na medida em que o ambiente da UTIN é marcado por um excesso de estímulos, aos quais o bebê não está habituado e tampouco preparado para lidar, como luzes fortes, sons de equipamentos, telefone e conversas constantes, que acabam interferindo no ciclo de sono de cada bebê. Além do ambiente não favorecer positivamente o desenvolvimento do bebê, nota-se a falha de processos essenciais na vida inicial do mesmo, como a falta de uma mãe suficientemente boa, provedora de um ambiente facilitador, capaz de identificar e suprir tanto as necessidades fisiológicas quanto as necessidades afetivas do filho.

A necessidade da separação que se dá pela hospitalização do bebê torna a mãe incapacitada de desempenhar suas funções maternas, ficando o bebê aos cuidados da equipe da UTIN. Esta, por sua vez, não dispõe de um preparo emocional e biológico que a ligue ao bebê, assim, a equipe acaba cumprindo as tarefas exigidas pela rotina hospitalar, atendendo cada recém-nascido conforme o seu tempo e disponibilidade de forma mais mecânica do que afetiva, sem profundo envolvimento. Foi possível perceber que somente as necessidades básicas dos bebês são satisfeitas, posto que o ato de trocar, limpar e alimentar se restringe à tarefa, sem o envolvimento do toque, da carícia, do olhar e de uma ligação afetiva, pois cada profissional é responsável por mais de um bebê.

A necessidade que leva cada enfermeira a cuidar de vários bebês ao mesmo tempo faz com que não consiga atender o bebê em tempo integral, ficando este à mercê das suas próprias dificuldades. $\mathrm{O}$ fato de ouvir o seu choro em poucos momentos da observação pode estar relacionado à desistência e desesperança deste bebê em en- 
contrar o auxílio do seu cuidador, que o leva a vivenciar sentimentos de desintegração e desamparo (Winnicott, 2012).

Através deste estudo, também buscou-se verificar se há prejuízo na relação mãe-bebê quando o mesmo nasce prematuramente e necessita ficar hospitalizado. Os achados desta pesquisa indicam que esta relação é prejudicada, primeiramente, pela separação prematura da mãe com o bebê através do parto e, posteriormente, pela hospitalização do mesmo. Durante este período, foi possível constatar que existem várias barreiras impedindo a interação e a proximidade da mãe com este bebê. A necessidade dos bebês permanecerem em incubadoras, monitorados por diversos equipamentos, impede ou pelo menos dificulta que a mãe inicie um contato aprofundado na busca de uma vinculação com o mesmo. Diante da impossibilidade de cuidar do próprio filho, a mãe é acometida por uma extrema ansiedade, o que dificulta ainda mais o contato com o bebê, que não responde de modo satisfatório aos estímulos excessivos da mãe naquele momento, como descrito no caso de Maria.

$\mathrm{Na}$ busca por constatar os sentimentos vivenciados pelas mães dos bebês internados, observou-se que duas mães experimentaram o sentimento de culpa em relação à prematuridade, configurada na busca de algo que explique o parto prematuro. Ambas as mães vivenciaram sentimentos de angústia, medo e insegurança, ao deixarem os filhos hospitalizados, ao mesmo tempo em que sentem a necessidade de crerem na recuperação destes. A impotência das mães em cuidar e levar o seu bebê para casa, reforça o sentimento de inferioridade, atingindo profundamente sua autoestima e a imagem que têm acerca de suas capacidades maternas e seu papel feminino. Constata-se que os sentimentos vivenciados pelas mães durante o período de hospitalização dos filhos são múltiplos e afetam não somente a relação com o seu bebê, mas a relação com o ambiente e consigo mesma.

Esta pesquisa não esgota o tema escolhido, mas mostra a amplitude com que este pode ser estudado. Em um caráter preventivo, sugere-se que o ambiente da UTIN se torne, de maneira geral, um ambiente mais humanizado, procurando amenizar os estímulos excessivos, quando assim for possível, para um melhor desenvolvimento do bebê. Em relação aos cuidados prestados pela equipe cuidadora, percebe-se que ela está tecnicamente preparada para cuidar dos bebês, porém, constata-se a ausência de um cuidado adequado e afetivo com os mesmos. Desta maneira, a presença de um profissional capacitado poderia qualificar esta equipe para aprender a interpretar e atender também as necessidades afetivas do bebê internado. Por fim, em relação aos sentimentos e experiências vivenciadas pelas mães, sugere-se, como proposta de intervenção, a criação de grupos de apoios, onde as mães possam trocar experiências, receber explicações e informações acerca do quadro do filho, o que as auxiliaria frente ao processo vivido.

Além disso, sugere-se criar um espaço que viabilize e facilite o contato da mãe com o filho internado, a fim de reestabelecer o vínculo afetivo e melhorar a relação mãe-bebê. Este processo pode ser possível com a implantação do método canguru na UTIN observada, que contribui de forma significativa para o desenvolvimento do bebê prematuro (Menezes, Garcia, Melo, \& Cipolotti, 2014). O método em questão viabiliza o contato precoce entre a mãe e o bebê hospitalizado, permitindo que esta participe mais efetivamente e por mais tempo dos cuidados oferecidos ao bebê, que é estimulado através do contato direto com a pele da mãe, facilitando a amamentação e auxiliando na vinculação da díade.

Espera-se que esse estudo possa contribuir para que os profissionais interessados e envolvidos com a temática em questão, possam refletir e intervir dentro das possiblidades que cada um possui, para que a clínica de bebês possa cada vez mais ser um tema estudado, valorizado e a partir disso surjam intervenções para melhorar o atendimento e também a qualidade de vida prestada a dupla mãe/bebê, buscando promover assim, um bom desenvolvimento psíquico deste bebê.

\section{Referências}

Brazelton, T. B. (1988). O desenvolvimento do apego: Uma família em formação. Porto Alegre, RS: Artes Médicas. 
Brazelton, T. B., \& Cramer, B. G. (1992). As primeiras relações. São Paulo, SP: Martins Fontes.

Debray, R. (1988). Bebês/mães em revolta. Porto Alegre, RS: Artes Médicas.

Diedrich, M. M. (2009). Bê-a-bá da metodologia de trabalhos acadêmicos e cientificos: Uma orientação prática a alunos de graduação e pós-graduação (2. ed.). Passo Fundo, RS: IMED.

Donelli, T. M. S. (2011). Considerações sobre a clínica psicológica com bebês que experimentaram internação neonatal. Gerais: Revista Interinstitucional de Psicologia, 4(2), 228-241.

Duarte, A. D. S., Santos, W. D. S., Silva, L. D. B. D., Oliveira, J. D. D., \& Sampaio, K. J. A. D. J. (2010). Promoção da saúde às genitoras de bebês prematuros: Ação da enfermagem na alta hospitalar. Revista da Rede de Enfermagem do Nordeste, 11(3), 162-170.

Emidio, T. S. (2008). Diálogos entre feminilidade e maternidade: Um estudo sob o olhar da mitologia e da psicanálise (Dissertação de mestrado em Psicologia, Universidade Estadual Paulista, São Paulo, SP, Brasil).

Ferrari, A. G., \& Donelli, T. M. S. (2010). Tornar-se mãe e prematuridade: Considerações sobre a constituição da maternidade no contexto do nascimento de um bebê com muito baixo peso. Contextos Clínicos, 3(2), 106-112.

Fraga, I. T. G., \& Pedro, E. N. R. (2004). Sentimentos das mães de recém-nascidos prematuros: Implicações para a enfermagem. Revista Gaúcha de Enfermagem, 25(1), 89-97.

Fulgencio, L. (2007). Winnicott's rejection of the basic concepts of Freud's metapsychology. The International Journal of Psychoanalysis, 88(2), 443-461. doi:10.1516/W543-2117-1031-716J

Fundo das Nações Unidas para a Infância - Brasil. (s.d.). Estudo faz alerta sobre a situação da prematuridade no Brasil. Recuperado em https:// www.unicef.org/brazil/pt/media_25849.html

Klaus, M. H., \& Kennel, J. H. (1993). Pais/bebês: A formação do apego. Porto Alegre, RS: Artes Médicas.

Lara, K. L., \& Kind, L. (2014). Processos de subjetivação vivenciados por mães em uma unidade de neonatologia. Psicologia em Estudo, 19(4), 575 585. doi:10.1590/1413-73722157901

Lebovici, S. (1987). O bebê, a mãe e o psicanalista. Porto Alegre, RS: Artes Médicas.
Marconi, M. A., \& Lakatos, E. M. (2006). Técnicas de pesquisa: Planejamento execução de pesquisas, amostragens e técnicas de pesquisa, elaboração, análise e interpretação dos dados (6. ed.). São Paulo, SP: Atlas.

Mathelin, C. (1999). O sorriso da Gioconda: Clínica psicanalítica com os bebês prematuros. Rio de Janeiro, RJ: Cia. de Freud.

Meio, M. D. B. (1999). Como estão sobrevivendo os pequenos prematuros? (Dissertação de mestrado em Medicina, Instituto de Medicina Social, Rio de Janeiro, RJ, Brasil).

Menezes, M. A. D. S., Garcia, D. C., Melo, E. V., \& Cipolotti, R. (2014). Recém-nascidos prematuros assistidos pelo Método Canguru: Avaliação de uma coorte do nascimento aos seis meses. Revista Paulista de Pediatria, 32(2), 171-177. doi:10.1590/0103-0582201432213113

Mussen, P. H., Conger, J. J., \& Kagan, J. (2001). Desenvolvimento da personalidade infantil (7. ed.). São Paulo, SP: Harbra.

Nascimento, M. M. (2012). UTI neonatal: Ambiente de expectativas ou de estresse? Recuperado em http://artigos.psicologado.com/atuacao/psicologia-hospitalar/uti-neonatal-ambiente-de-expectativas-ou-de-estresse\#ixzz2SRO73iJL

Oliveira, K. de, Veronez, M., Higarashi, I. H., \& Corrêa, D. A. M. (2013). Vivências de familiares no processo de nascimento e internação de seus filhos em UTI neonatal. Escola Anna Nery, 17(1), 46-53. doi:10.1590/S1414-81452013000100007

Pacheco, S. T. D. A., Silva, A. M. D., Lioi, A., \& Rodrigues, T. A. F. (2012). O cuidado pelo enfermeiro ao recém-nascido prematuro frente à punção venosa. Revista de Enfermagem da UERJ, 20(3), 306-311.

Padovani, F. H. P., Linhares, M. B. M., Carvalho, A. E. V., Duarte, G., \& Martinez, F. E. (2004). Avaliação de sintomas de ansiedade e depressão em mães de neonatos pré-termo durante e após hospitalização em UTI-Neonatal. Revista Brasileira de Psiquiatria, 26(4), 251-254. doi:10.1590/ S1516-44462004000400009

Pedroso, G. E. R., \& Bousso, R. S. (2003). O significado de cuidar da família na UTI neonatal: Crenças da equipe de enfermagem. Ciência, Cuidado e Saúde, 2(2), 123-129.

Portal Brasil. (2012). Brasil está entre os dez países com o maior número de partos prematuros, aponta OMS. Recuperado em http://www.brasil. 
gov.br/noticias/arquivos/2012/05/04/brasil-estaentre-os-dez-paises-com-o-maior-numero-departos-prematuros-aponta-oms

Santos, V., \& Candeloro, R. J. (2006). Trabalhos acadêmicos: Uma orientação para a pesquisa e normas técnicas. Porto Alegre, RS: AGE.

Scochi, C. G. S., Kokuday, M. L. P., Riul, M. J. S., Rossanez, L. S. S., Fonseca, L. M. M., \& Leite, A. M. (2003). Incentivando o vínculo mãe-filho em situação de prematuridade: As intervenções de enfermagem no hospital das clínicas de Ribeirão Preto. Revista Latino-Americana de Enfermagem, 11(4), 539-543. doi:10.1590/S010411692003000400018

Scortegagna, S. A., Miranda, C. A., Morsch, D. S., Carvalho, R. A., Biasi, J., \& Cherubini, F. (2005). O processo interativo mãe-bebê pré-termo. Psic: Revista da Vetor Editora, 6(2), 61-70.

Shaffer, D. R. (2005). Desenvolvimento e personalidade da criança (6. ed.). São Paulo, SP: Pioneira Thomson Learning.
Vidal, M. (2011). Alta hospitalar e reinternação de bebê prematuro: Uma reflexão sobre o acesso aos serviços de saúde. Mental, 9(17), 537-558.

Winnicott, D. W. (1975). O brincar e a realidade. Rio de Janeiro, RJ: Imago.

Winnicott, D. W. (2000). A preocupação materna primária. Rio de Janeiro, RJ: Imago.

Winnicott, D. W. (2006). Os bebês e suas mães (3. ed.). São Paulo, SP: Martins Fontes.

Winnicott, D. W. (2012). A criança e o seu mundo (6. ed.). Rio de Janeiro, RJ: LTC.

Yin, R. K. (2005). Estudo de caso: Planejamento e métodos (3. ed.). Porto Alegre, RS: Bookman.

Recebido: $24 / 08 / 2015$

$1^{a}$ revisão: $12 / 01 / 2016$ Aceite final: 02/02/2016 